\title{
Structure-reactivity Studies of Simple 4-hydroxyprolinamide Organocatalysts in the Asymmetric Michael Addition Reaction of Aldehydes to Nitroolefins
}

\author{
Fintan Kelleher \\ Technological University Dublin, fintan.kelleher@tudublin.ie \\ John Watts \\ Technological University Dublin \\ Lien Luu \\ Technological University Dublin
}

See next page for additional authors

Follow this and additional works at: https://arrow.tudublin.ie/ittsciart

Part of the Computer Sciences Commons, and the Organic Chemistry Commons

\section{Recommended Citation \\ Kelleher, F., Watts, J., Luu, L., McKee, V., Carey, E.: Structure-reactivity Studies of Simple 4-hydroxyprolinamide Organocatalysts in the Asymmetric Michael Addition Reaction of Aldehydes to Nitroolefins. Advanced Synthesis and Catalysis, vol. 354 (6), p. 1035-1042, April 16, 2012.}

This Article is brought to you for free and open access by the School of Science and Computing at ARROW@TU Dublin. It has been accepted for inclusion in Articles by an authorized administrator of ARROW@TU Dublin. For more information, please contact arrow.admin@tudublin.ie, aisling.coyne@tudublin.ie, gerard.connolly@tudublin.ie.

Funder: Irish Government's National Development Plan 


\section{Authors}

Fintan Kelleher, John Watts, Lien Luu, Vickie McKee, and Ed Carey

This article is available at ARROW@TU Dublin: https://arrow.tudublin.ie/ittsciart/18 
DOI: 10.1002/adsc.201100028

\title{
Structure-Reactivity Studies of Simple 4-Hydroxyprolinamide Organocatalysts in the Asymmetric Michael Addition Reaction of Aldehydes to Nitroolefins
}

\author{
John Watts, ${ }^{\mathrm{a}}$ Lien Luu, ${ }^{\mathrm{a}}$ Vickie McKee, ${ }^{\mathrm{b}}$ Ed Carey, ${ }^{\mathrm{a}}$ and Fintan Kelleher ${ }^{\mathrm{a}, *}$ \\ a Molecular Design and Synthesis Group, Department of Science, Institute of Technology Tallaght, Dublin 24, Ireland \\ Fax: (+353)-1-404-2700; phone: (+353)-140-42869; e-mail: Fintan.kelleher@ittdublin.ie \\ b Chemistry Department, Loughborough University, Loughborough, Leicestershire, LE11 3TU, U.K.
}

Received: January 13, 2011; Revised: December 5, 2011; Published online: $\mathbf{\square}$ U1, 0000

Supporting information for this article is available on the WWW under http://dx.doi.org/10.1002/adsc.201100028.

A series of simple 4-hydroxyprolinamides was synthesised and they were found to act as organocatalysts for the asymmetric conjugate addition of aldehydes to nitroolefins in excellent yields $(98 \%)$, with complete diastereoselectivity (99:1, syn:anti) and enantioselectivity $(98 \%$ ee for $s y n)$. Furthermore, the use of low catalyst loadings $(5 \mathrm{~mol} \%)$ and a low aldehyde molar excess (1.5 equivalents) were achieved.

\section{Introduction}

The Michael addition reaction is one of the fundamental $\mathrm{C}-\mathrm{C}$ bond forming reactions in organic chemistry,$^{[1]}$ while the field of organocatalysis ${ }^{[2]}$ has seen an explosion of interest in the last decade, with just over 1000 journal papers being published in the area in 2010 alone, with a similar number highly likely for 2011. ${ }^{[3]}$ Many L-proline-derived compounds have found use as organocatalysts in the asymmetric Michael addition reaction of aldehydes and ketones to nitroolefins, with the products being produced in high yields, with excellent diastereo- and enantioselectivities (Figure 1)..$^{[2,46]}$ More recently highly efficient catalyst systems for this transformation have been developed and are the benchmark for all new catalysts. Ma was able to achieve high yields and selectivities using only $0.5 \mathrm{~mol} \%$ of $\mathbf{4}$ and 1.5 equivalents of aldehyde in the presence of benzoic acid as an additive. ${ }^{[4]}$ However, Lombardo recently reported the use of the ion-tagged diphenylprolinol silyl ether 7 which achieves enantiomeric excesses of $>99.5 \%$ at low catalyst loadings $(0.25-5 \mathrm{~mol} \%)$, and uses only a slight excess of aldehydes (1.2-2 molar equivalents) $\cdot{ }^{[5]} \mathrm{Ni}$ achieved excellent yields and selectivities with a water-soluble derivative of $\mathbf{4}$ using catalyst
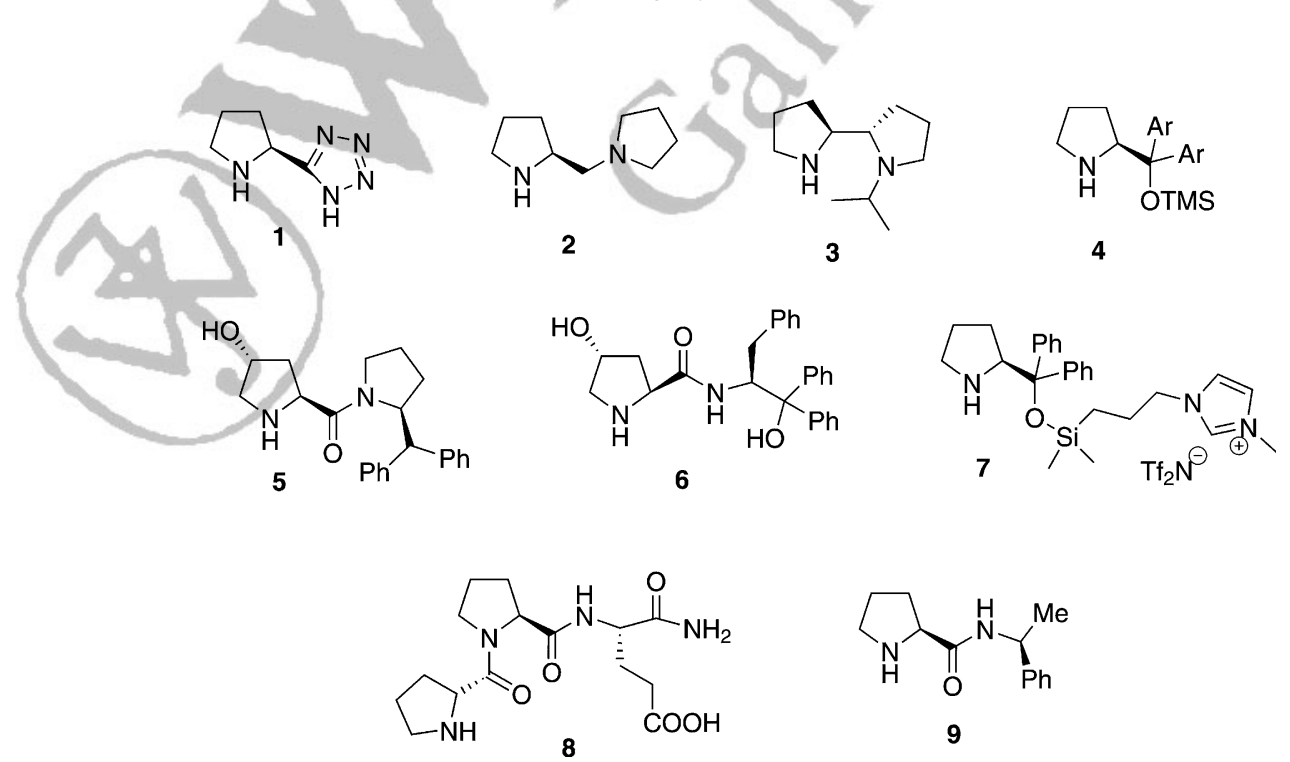

Figure 1. Proline and 4-hydroxyproline derived organocatalysts. ${ }^{[3-10]}$ 
loadings of only $2-3 \%{ }^{[6]}$ The most efficient catalyst reported to date is the tripeptide $\mathbf{8}$ described by Wennemers. ${ }^{[7]}$ This catalyst is highly efficient at levels of only $0.1-0.2 \mathrm{~mol} \%$, even with the nitroalkene in excess, giving high yields and selectivities for a range of aldehydes and nitroalkenes. The usefulness of the products from these reactions resides in the potential for further reaction or the transformation of both the nitro and carbonyl functionalities.

There is a continuing requirement for the development of new efficient catalysts for this and other important transformations, as well as their use in cascade syntheses of complex products. An understanding of the mechanisms ${ }^{[8]}$ and structure-reactivity relationships of existing catalysts is also needed to help with the design and development of new catalytic systems.

Our group recently reported on the use of prolinederived spirolactams, as well as more conformationally flexible prolinamide analogues (e.g., 9), as asymmetric organocatalysts for the Michael addition of aldehydes to nitrostyrenes ${ }^{[9]}$ High yields (98\%) as well as excellent diastereoselectivities (49:1, syn:anti) were achieved, for $\mathbf{9}$, while the enantiomeric excess (ee) was $81 \%$. In this study it was found that a methyl group in the pyrrolidine 2-position was detrimental to stereocontrol due to unfavourable steric interactions. Thus there was a need to improve the enantioselectivity of the spirolactam and prolinamide catalysts to give catalysts with full stereocontrol. In 2006, Palomo reported on the use of trans-4-hydroxyprolinamides (5, Figure 1$)$ as a catalyst in the asymmetric Michael addition reaction of aldhydes to nitroolefins. ${ }^{[10]}$ The 4hydroxy group was responsible for the high enantioselectivity observed $(98 \%$ ee $)$ by directing the facial approach of the $\beta$-nitrostyrene through a hydrogenbonding interaction. More recently Nakano used this methodology to prepare an efficient catalyst $(\mathbf{6}$, Figure 1) for both the asymmetric Michael addition and aldol reactions. ${ }^{[11]} \mathrm{A}$ study was thus undertaken to examine the effect of a 4-hydroxy group on the enantioselectivity of our simple prolinamide catalysts. Furthermore it was of interest to examine whether the hydrogen-bonding ability of the 4-hydroxy group, and its very efficient facial directing ability, would be able to overcome the presence of a sterically hindering methyl group in the pyrrolidine 2-position. This would therefore lead to an improved understanding of the structure-reactivity relationships of these catalytic systems.

\section{Results and Discussion}

The starting material for the syntheses was trans-4-hydroxy-L-proline which was fully protected as its TBDMS ether, methyl ester and $N$-Boc derivative 10, according to literature methods. ${ }^{[12]}$ The best result for $\alpha$-methylation was achieved using LiHMDS at $-20^{\circ} \mathrm{C}$, and treatment of the resulting enolate with methyl iodide, which gave the fully separable diastereoisomeric $\alpha$-methyl esters $\mathbf{1 1}$ and $\mathbf{1 2}$, in a combined isolated yield of $74 \%$ (Scheme 1). Separately each ester was hydrolysed to give the free carboxylic acids 13 and 14. In order to compare directly with our previously developed prolinamide catalysts, ${ }^{[8]}$ the $\alpha$-methylbenzylamine-derived 4-hydroxyprolinamides were prepared. Coupling of $\mathbf{1 3}$ separately with $(R)$ - or $(S)$ $N$, a-dimethylbenzylamine in the presence of HATU gave the $N$-methylated prolinamides $\mathbf{1 5 b}$ and $\mathbf{1 6 b}$, in low yields of 33 and $31 \%$ respectively, due to the highly hindered nature of both coupling partners. However, when similar couplings with the diastereoisomeric acid 14 were attempted no products were isolated. This is most likely due to the fact that the carboxylic acid and TBDMS ether groups are on the same side of the pyrrolidine ring, as well as the sterically hindered nature of the amines being used. In this case it was first necessary to remove the TBDMS protecting group, with TBAF, to give the 4-hydroxy carboxylic acid 21. Coupling with the $(R)$ - or $(S)-N, \alpha-$ dimethylbenzylamines was now successful with the desired prolinamides $\mathbf{2 2 b}$ and $\mathbf{2 3 b}$ being isolated in 27 and $31 \%$ yields, respectively. Deprotection of the TBDMS groups of $\mathbf{1 5 b}$ and $\mathbf{1 6 b}$ was achieved to give 17b and 18b. The Boc group of all four diastereoisomers was removed using 50\% TFA/DCM, where the isolation of the free amines 19b, 20b, 24b and 25b proved problematic with all isomers giving poor yields of $20-25 \%$. This was due to the high aqueous solubility of the products and difficulty with their extraction.

The corresponding $\alpha$-methyl $N-\mathrm{H}$ prolinamide analogues were prepared in a similar manner by coupling of acids $\mathbf{1 3}$ and $\mathbf{2 1}$ with the less hindered $(R)$ - or $(S)$ $\mathrm{N}$-methylbenzylamines giving the coupled products 15a, 16a, 22a and 23a in slightly improved yields of $39-50 \%$. Removal of the TBDMS groups of 15a and 16a gave 17a and 18a. Finally removal of all the Boc protecting groups, as before, gave the four diastereoisomeric $N-\mathrm{H}$ prolinamides 19a, 20a, 24a and 25a. Only compound 17a gave crystals suitable for X-ray crystal structure determination which clearly showed the $(2 S, 4 R, 8 S)$ configuration (Figure 2). This then allowed for the assignment of the absolute configuration of all the compounds prepared.

As the presence of the $\alpha$-methyl group was previously found to be detrimental to efficient catalysis, ${ }^{[8]}$ the analogous simple 4-hydroxy prolinamide $\mathrm{N}-\mathrm{H}$ and $\mathrm{N}$-methyl catalysts were prepared in a similar manner to that outlined (vide supra), but using the $N$-Boc TBDMS ether protected carboxylic acid 26, which was prepared from the methyl ester $\mathbf{1 0}$ by hydrolysis (Scheme 2). The $\mathrm{N}$-H prolinamides 27 and $\mathbf{2 8}$ were 


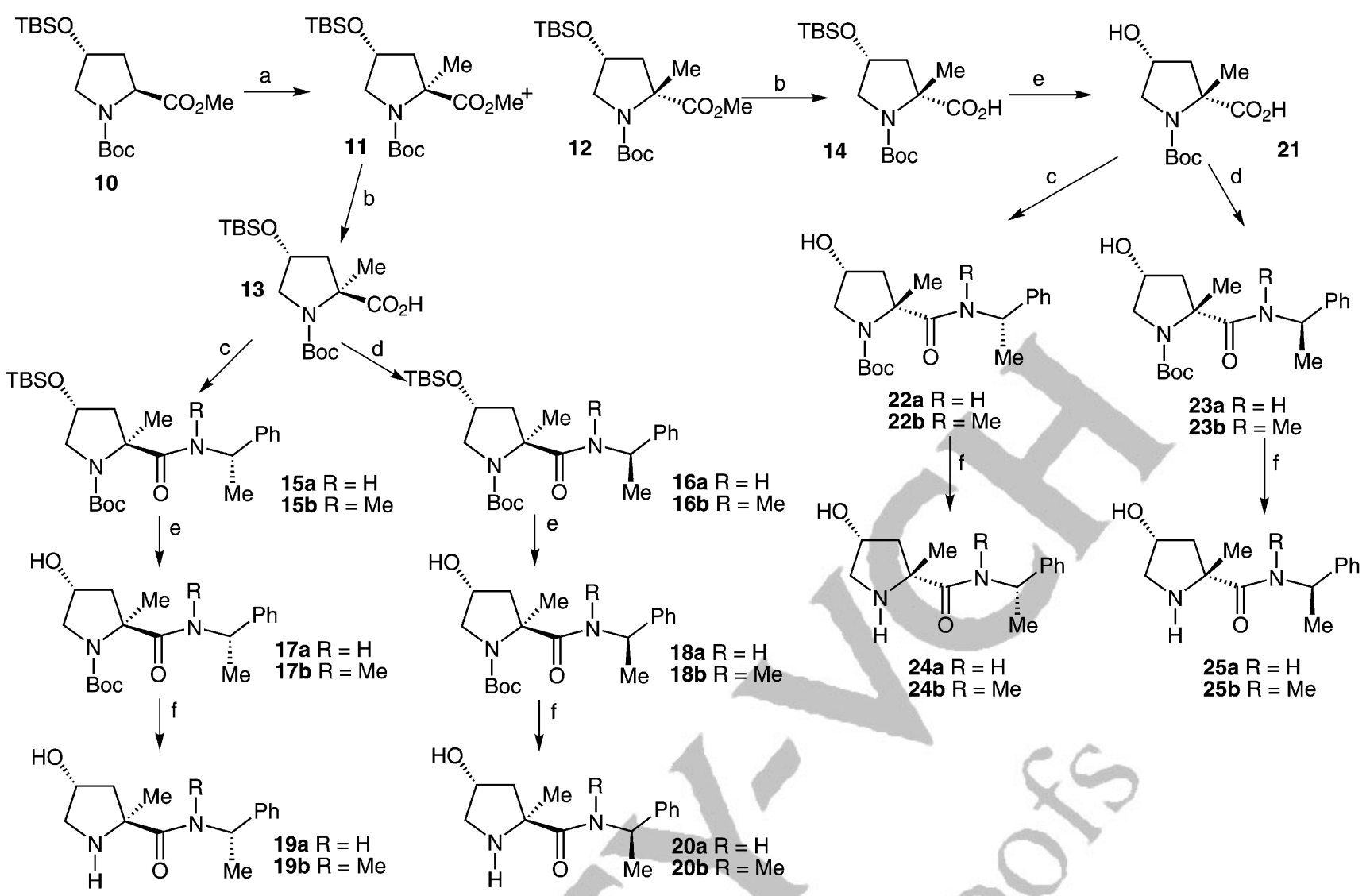

Scheme 1. Synthesis of prolinamides 19, 20, 24 and 25. Reagents and conditions: a) i) LiHMDS, THF, $-20^{\circ} \mathrm{C}$; ii) $\mathrm{CH}_{3} \mathrm{I}, \mathrm{THF}$, $18 \mathrm{~h},-20^{\circ} \mathrm{C}$ to room temperature; b) $\mathrm{NaOH}$ in $\mathrm{MeOH} / \mathrm{H}_{2} \mathrm{O}, \Delta$; c) For 15a and 22a: (S)-1-phenylethylamine, HATU, DIPEA, DMF, room tempearture; for 15b and 22b: $(S)-N, \alpha$-dimethylbenzylamine, HATU, DIPEA, DMF, rt; d) For 16a and 23a: $(R)$-1-phenylethylamine, HATU, DIPEA, DMF, room temperature; for $\mathbf{1 6 b}$ and 23b: $(R)$ - $N, \alpha$-dimethylbenzylamine, HATU, DIPEA, DMF, room temperature; e) $1 \mathrm{M} \mathrm{TBAF}$ in THF, $0{ }^{\circ} \mathrm{C}$; f) $50 \% \mathrm{TFA} / \mathrm{DCM}$.

obtained in much improved yields of $68 \%$ and $72 \%$, respectively. $N$-Methylation was achieved by deprotonation with LiHMDS and methylation with methyl iodide giving the desired compounds 29 and 31, with both being obtained in a $58 \%$ yield. As before all protecting groups were removed giving the four simple 4hydroxy prolinamides 30, 32, 33 and 34.

All the prepared compounds were assessed as organocatalysts in the model reaction of valeraldehyde with trans- $\beta$-nitrostyrene (Table 1$)$. For comparison with our previously published results ${ }^{[8]}$ the reaction conditions were kept constant, i.e., the solvent used was DCM, with $5 \mathrm{~mol} \%$ catalyst, 1.5 mole equivalents of valeraldehyde, at room temperature for $48 \mathrm{~h}$. The two $\alpha$-methyl compounds $\mathbf{1 9 b}$ and $\mathbf{2 0 b}$ with the $N$ methyl amide trans to the 4-hydroxy group (entries 1 and 2) show good yields, poor diastereoselectivity, but reasonable enantiomeric excesses of the major syn product. However, the two $\alpha$-methyl compounds $\mathbf{2 4 b}$ and 25b with the $N$-methyl amide cis to the 4-hydroxy group show much reduced yields, diastereoselectivities and enantioselectivities (entries 3 and 4). The four corresponding $N-\mathrm{H}$ compounds (19a, 20a, 24a

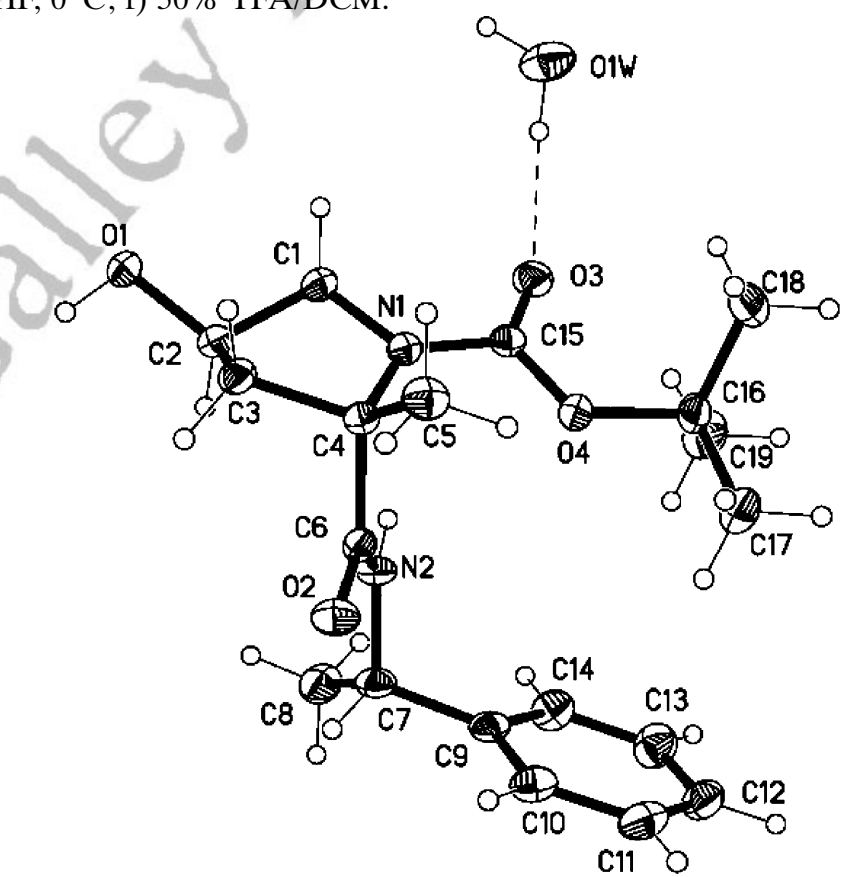

Figure 2. X-ray crystal structure of $\mathbf{1 7} \cdot \mathbf{a} \cdot \mathbf{H}_{2} \mathbf{O}$ showing $2 S, 4 R, 8 S$ stereochemistry. The dashed line shows a hydrogen bond. 


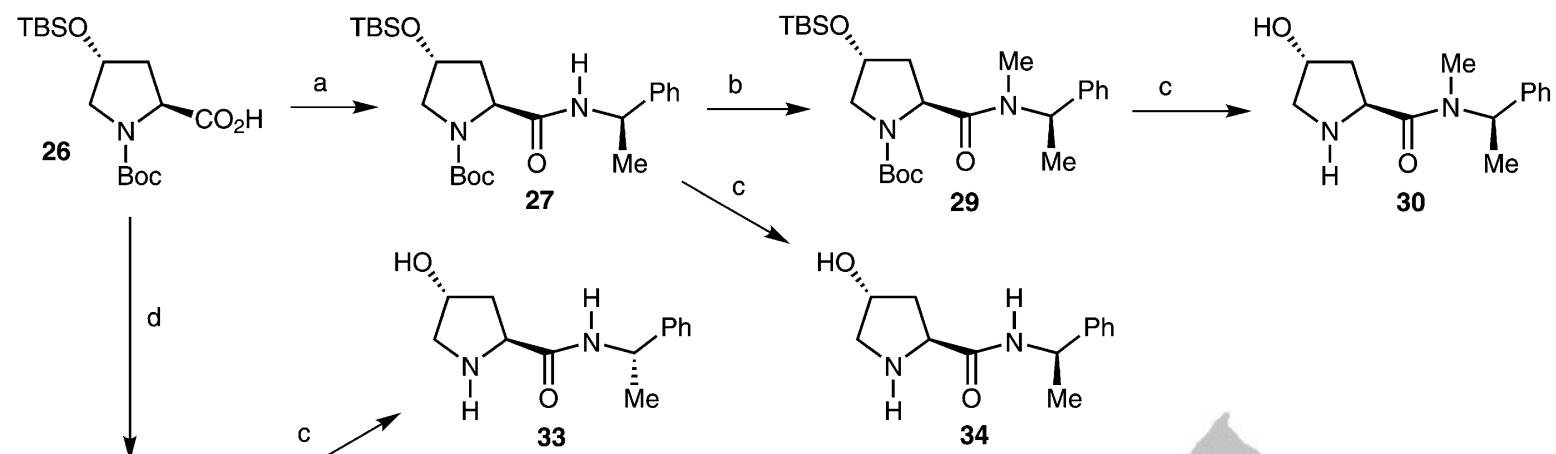

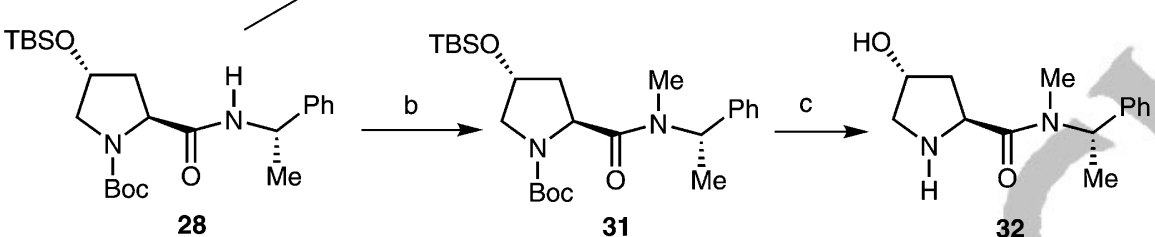<smiles>O=C(O)C1C[C@@H](O)CN1C(=O)O</smiles>

35<smiles>CC(NC(=O)C1C[C@@H](O)CN1)c1cccc2ccccc12</smiles>

36

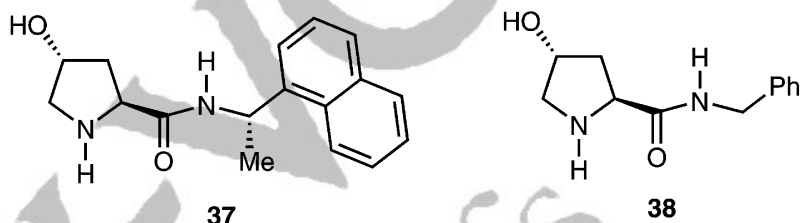

37

38

Scheme 2. Synthesis of prolinamides 30, 32-34 and 36-38. Reagents and conditions: a) (R)-1-phenylethylamine, EDC, DMAP, DCM, $16 \mathrm{~h}$, room temperature; b) i) LiHMDS, THF, $-20^{\circ} \mathrm{C}$; ii) $\mathrm{CH}_{3} \mathrm{I}, \mathrm{THF}, 18 \mathrm{~h},-20^{\circ} \mathrm{C}$ to room temperature; c) i) $1 \mathrm{M}$ TBAF in THF, $0^{\circ} \mathrm{C}$; ii) 50\% TFA/DCM; d) $(S)$-1-phenylethylamine, EDC, DMAP, DCM, $16 \mathrm{~h}$, room temperature.

Table 1. Optimisation of catalyst for Michael addition of valeraldehyde to trans- $\beta$-nitrostyrene.

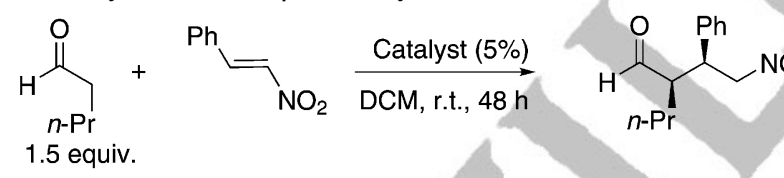

\begin{tabular}{lllll}
\hline Entry & Catalyst & Yield $^{[\mathrm{a}]}$ & $d r^{[\mathrm{b}]}$ & $e e^{[\mathrm{c}]}$ \\
\hline 1 & $\mathbf{1 9 b}$ & 98 & $59: 41$ & $83^{[\mathrm{d}]}$ \\
2 & $\mathbf{2 0 b}$ & 98 & $62: 38$ & $77^{[\mathrm{d}]}$ \\
3 & $\mathbf{2 4 b}$ & 60 & $59: 41$ & 36 \\
4 & $\mathbf{2 5 b}$ & 55 & $62: 38$ & 24 \\
5 & $\mathbf{1 9 a}$ & 98 & $68: 32$ & $26^{[\mathrm{d}]}$ \\
6 & $\mathbf{2 0 a}$ & 98 & $54: 46$ & $58^{[\mathrm{d}]}$ \\
7 & $\mathbf{2 4 a}$ & 38 & $53: 47$ & 37 \\
8 & $\mathbf{2 5 a}$ & 34 & $52: 48$ & 21 \\
9 & $\mathbf{3 0}$ & 98 & $78: 22$ & 71 \\
10 & $\mathbf{3 2}$ & 98 & $91: 09$ & 82 \\
$\mathbf{1 1}$ & $\mathbf{3 3}$ & $\mathbf{9 8}$ & $\mathbf{9 8 : 0 2}$ & $\mathbf{9 8}$ \\
$\mathbf{1 2}$ & $\mathbf{3 4}$ & $\mathbf{9 8}$ & $\mathbf{9 9 : 0 1}$ & $\mathbf{9 8}$ \\
13 & $\mathbf{3 6}$ & 98 & $87: 13$ & 72 \\
14 & $\mathbf{3 7}$ & 98 & $92: 08$ & 78 \\
15 & $\mathbf{3 8}$ & 98 & $93: 07$ & 80 \\
\hline
\end{tabular}

[a] Isolated yield after column chromatography.

[b] The syn:anti ratio was determined by ${ }^{1} \mathrm{H}$ NMR spectroscopy.

[c] The ee of the syn isomer $(R, S)$ as determined by Chiral HPLC.

[d] $(S, R)$-enantiomer of product. and 25a) show similar results and trends (entries 5 to 8). Removal of the $\alpha$-methyl group using the simple $\mathrm{N}$-methyl prolinamides $\mathbf{3 0}$ and $\mathbf{3 2}$ show improved results (entries 9 and 10) with $98 \%$ isolated yields, hugely improved diastereoselectivity and enantiomeric excesses back to $71 \%$ and $82 \%$. The simplest hydroxyprolinamides $\mathbf{3 3}$ and $\mathbf{3 4}$ gave exceptional levels of control with again isolated yields of $98 \%$, excellent diastereoselectivity ( 99:1, syn:anti) and almost complete enantioselectivity $(98 \% e e)$.

The results observed can be explained by looking at the proposed transition state model for the reaction (Figure 3). For catalysts $\mathbf{3 3}$ and $\mathbf{3 4}$ the hydroxy group directs the $S i$ face of the trans- $\beta$-nitrostyrene preferentially to the $S i$ face of the more stable $E$ anti-enamine (Si,Si-1 approach in Figure 3). The other Si,Si approach $(\boldsymbol{S i}, \boldsymbol{S i - 2})$ is much less likely due to the steric interaction between the incoming $\beta$-nitrostyrene and the amide side-chain of the enamine.

There are two probable approaches that would lead to the minor enantiomeric product $(\boldsymbol{R e}, \boldsymbol{R e}-\boldsymbol{1}$ and $\boldsymbol{R e}, \boldsymbol{R e}-\mathbf{2}$ in Figure 3). For $\boldsymbol{R e}, \boldsymbol{R e}-\mathbf{2}$ the amide sidechain sterically hinders approach of the $\beta$-nitrostyrene to the $R e$ face of the enamine. The $\boldsymbol{R e}, \boldsymbol{R e}-\mathbf{1}$ trajectory is the more likely but it is probable that the 4-hydroxy group is too far away to direct the $\beta$-nitrostyrene. Thus, it is likely that a combination of the effect of the amide side-chain, the more likely enamine strucu- 


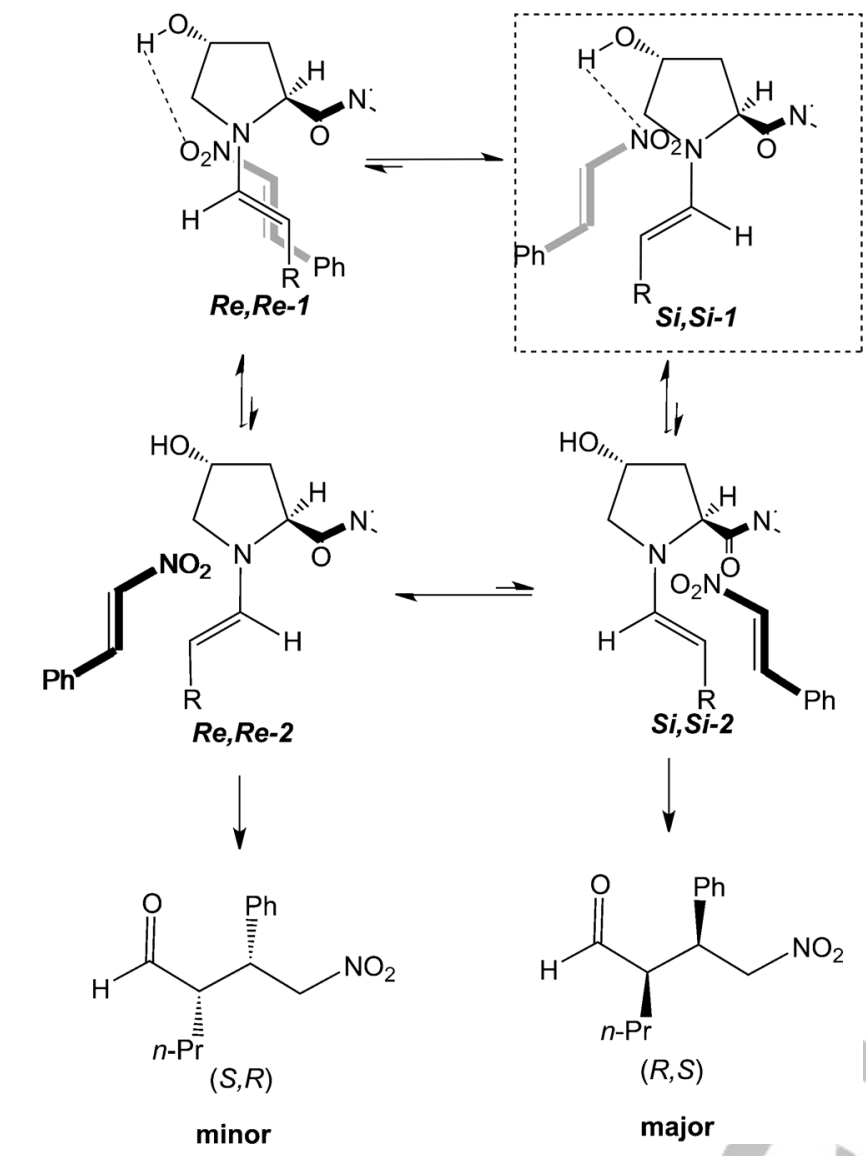

Figure 3. Proposed transition-state model for 4-hydroxyprolinamide catalysts $\mathbf{3 3}$ and $\mathbf{3 4}$.

tre and the 4-hydroxy group which dictates the level of stereocontrol stereocontrol observed. The optimal combination of effects occurs for $\mathbf{S i}, \mathbf{S i}-\mathbf{1}$ approach giving the observed stereocontrol (see also computational studies below).

It was now of interest to examine whether the prolinamide $N$-1-phenylethyl side-chain was optimal for reactivity. Three compounds with increased or decreased steric requirements were targeted so the $N$-1(1-naphthylethyl) (36 and 37) and $N$-benzyl (38) compounds were also prepared (Scheme 2), by a similar route to the $N$-1-phenylethyl derivatives except $N$ Boc-trans-4-hydroxy-L-proline 35 was the starting material (see Supporting Information). The results for these compounds in the model reaction of valeraldehyde with trans- $\beta$-nitrostyrene are shown in Table 1 , entries 13-15. It can be seen that changing the prolinamide side-chain to either a more, or less, sterically hindered moiety is detrimental to the selectivity ( $d r$ and $e e$ ) of the reaction. Thus the $N$-1-phenylethyl side-chain is optimal in this catalyst system for the reaction under study.

For the short-chain aldehyde both catalysts (33 and 34) show reduced diastereo- and enantioselectivity (entries 3 and 4), while both retain excellent diaster- eoselctivity and enantioselectivity for the branched aldehyde (entries 5 and 6). For the substituted $\beta$-nitrostyrenes the electron-donating methyl and methoxy groups show reduced diastereo- and enantioselectivity for both catalysts (entries 7-10). The results for the 4methyl case (entries 7 and 8) is surprising with a much reduced yield along with very poor diastereoand enantioselectivities. In these cases the reactions appeared slightly cloudy in appearance which may be due to solubility issues which affected both the yield and stereoselectivity. However, the 4-chloro analogue retains high levels of diastereoselectivity, as well as complete enantioselectivity (99\% ee, entries 11 and 12). A preliminary result for the use of the catalysts for the addition of cyclohexanone to trans- $\beta$-nitrostyrene shows that they are also very reactive in these cases (entries 13 and 14). It was however necessary to use 20 molar equivalents of cyclohexanone, in the absence of solvent, and $10 \mathrm{~mol} \%$ of the catalyst to achieve these results. This study is currently being extended in order to optimise the reaction conditions as well as examining the scope of the catalysts with different ketones and $\beta$-nitrostyrenes, while the reactivity of the catalysts in aqueous solutions is also being studied.

A closer examination of all the results in Table 1 and Table 2, as well as the proposed transition state

Table 2. Scope of catalysts $\mathbf{3 3}$ and $\mathbf{3 4}$ for Michael addition of aldehydes to trans- $\beta$-nitrostyrenes.

\begin{tabular}{|c|c|c|c|c|c|c|}
\hline Entry & Cat. & $\mathrm{R}$ & $\mathrm{Ar}$ & Yield $^{[a]}$ & $d r^{[\mathrm{b}]}$ & $e e^{[\mathrm{c}]}$ \\
\hline 1 & 33 & $n-\operatorname{Pr}$ & $\mathrm{Ph}$ & 98 & 98:02 & 98 \\
\hline 2 & 34 & $n$-Pr & $\mathrm{Ph}$ & 98 & 99:01 & 98 \\
\hline 3 & 33 & $\mathrm{CH}_{3}$ & $\mathrm{Ph}$ & 60 & 59:41 & 36 \\
\hline 4 & 34 & $\mathrm{CH}_{3}$ & $\mathrm{Ph}$ & 55 & $62: 38$ & 24 \\
\hline 5 & 33 & $i-\operatorname{Pr}$ & $\mathrm{Ph}$ & 98 & $68: 32$ & $26^{[\mathrm{d}]}$ \\
\hline 6 & 34 & $i-\operatorname{Pr}$ & $\mathrm{Ph}$ & 98 & $54: 46$ & $58^{[\mathrm{d}]}$ \\
\hline 7 & 33 & $n$-Pr & $p$-Me- $\mathrm{C}_{6} \mathrm{H}_{4}$ & 38 & $53: 47$ & 37 \\
\hline 8 & 34 & $n-\operatorname{Pr}$ & $p-\mathrm{Me}-\mathrm{C}_{6} \mathrm{H}_{4}$ & 34 & $52: 48$ & 21 \\
\hline 9 & 33 & $n-\operatorname{Pr}$ & $p-\mathrm{MeO}-\mathrm{C}_{6} \mathrm{H}_{4}$ & 98 & $78: 22$ & 71 \\
\hline 10 & 34 & $n-\operatorname{Pr}$ & $p-\mathrm{MeO}-\mathrm{C}_{6} \mathrm{H}_{4}$ & 98 & 91:09 & 82 \\
\hline 11 & 33 & $n-\operatorname{Pr}$ & $p-\mathrm{Cl}-\mathrm{C}_{6} \mathrm{H}_{4}$ & 98 & 98:02 & 98 \\
\hline 12 & 34 & $n$-Pr & $p-\mathrm{Cl}-\mathrm{C}_{6} \mathrm{H}_{4}$ & 98 & 99:01 & 98 \\
\hline 13 & 33 & $-^{[\mathrm{e}]}$ & $\mathrm{Ph}$ & 98 & $87: 13$ & 72 \\
\hline 14 & 34 & $-^{[\mathrm{e}]}$ & $\mathrm{Ph}$ & 98 & $92: 08$ & 78 \\
\hline
\end{tabular}

[a] Isolated yield after column chromatography.

[b] The syn:anti ratio was determined by ${ }^{1} \mathrm{H}$ NMR spectroscopy.

[c] The ee of the syn isomer $(R, S)$ as determined by Chiral HPLC.

[d] $(S, R)$-enantiomer of product.

[e] Cyclohexanone used. 


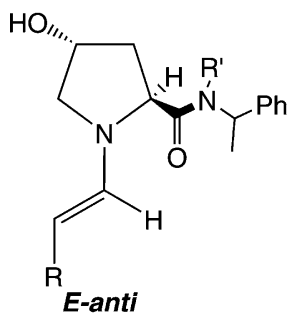

For $\mathbf{R}^{\prime}=\mathbf{H}$

$\mathrm{R}=n-\operatorname{Pr} 0.0$

$\mathrm{R}=\mathrm{Me} \quad 0.14$

$\mathrm{R}=i-\operatorname{Pr} 0.25^{\star}$

$\mathrm{R}=\mathrm{Et} \quad 0.22$

For $\mathbf{R}^{\prime}=\mathrm{Me}$

$\mathrm{R}=n-\operatorname{Pr} 0.14$

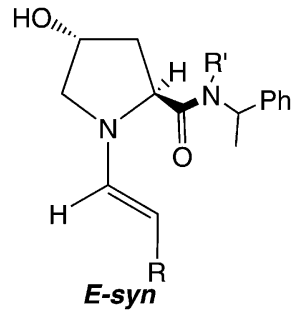

For $\mathbf{R}^{\prime}=\mathbf{H}$

$\mathrm{R}=n-\operatorname{Pr} 0.13$

$\mathrm{R}=\mathrm{Me} \quad 0.0$

$\mathrm{R}=i-\operatorname{Pr} \quad 0.0$

$\mathrm{R}=\mathrm{Et} \quad 0.0$

For $\mathbf{R}^{\prime}=\mathrm{Me}$

$\mathrm{R}=n-\operatorname{Pr} 0.0$

Figure 4. Relative energies of enamines (in $\mathrm{kcal} \mathrm{mol}^{-1}$ ).

model, shows there are some discrepancies. For example, if the amide side-chain is just acting as a steric blocking group (Figure 3 ) then it would be expected that similar results should be obtained for the catalysts with either an $\mathrm{N}$-H or $\mathrm{N}$-Me group in the sidechain (e.g., entry 9 versus entry 11 or entry 10 versus entry 12 in Table 1 ). The presence of the $N$-Me group clearly has a detrimental effect on the observed selectivity. This begs the question as to whether there is some role, for example, hydrogen-bonding, for the side-chain $N-\mathrm{H}$ which is not present for the $N$-Me cases. A large drop in selectivity is also observed when the aldehyde partner is changed. A shorter or branched chain leads to a dramatic drop in the stereocontrol of the reaction (entries 3-6 in Table 2). It was therefore decided to use computational studies to examine the relative energies of the different enamine structures, as well as possible transition states, in order to explain the observed results.

The energies of the various enamines were calculated at the B3LYP/6-31G ${ }^{*[13]}$ level of theory and the results show that both the structure of the side-chain amide and the aldehyde chain have an effect on the relative energies of the enamines. As expected, in all cases the $E$ rather $Z$ enamines were more stable. For the amide side-chain containing an $N$-H the E-anti enamine derived from valeraldehyde $(\mathrm{R}=n-\mathrm{Pr})$ is more stable by $0.13 \mathrm{kcal} \mathrm{mol}^{-1}$ (Figure 4). However, any change to the aldehyde chain $(\mathrm{R}=\mathrm{Me}, \mathrm{Et}$ or $i$-Pr) leads to the $E$-syn enamine being the more stable. For the branched aldehyde $(\mathrm{R}=i$-Pr $)$ there were a number of low energy conformations possible depending on the position of the two methyl groups of the isopropyl group, but a difference of $0.25 \mathrm{kcal}$ $\mathrm{mol}^{-1}$ was the smallest energy difference seen. Interestingly methylation of the amide side-chain nitrogen leads to a switch in the more stable enamine derived from valeraldehyde $(\mathrm{R}=n-\mathrm{Pr})$, where the $E$-syn enamine now is more stable by $0.14 \mathrm{kcal} \mathrm{mol}^{-1}$. From the transition state model outlined in Figure 3 the

Table 3. Energies of amide side-chain conformers (rotations around the 4 rotatable bonds shown were examined). $\mathrm{HO}$,

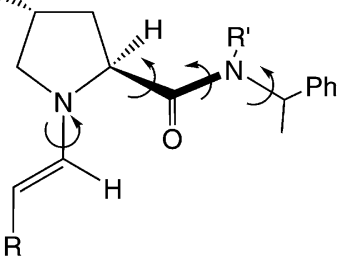

\begin{tabular}{lll}
\hline Conformer $^{[\mathrm{a}]}$ & $\mathrm{E}+\mathrm{ZPE}($ a.u. $)$ & $\Delta(\mathrm{E}+\mathrm{ZPE})\left(\mathrm{kcal} \mathrm{mol}^{-1}\right)$ \\
\hline$N-\mathrm{H}$ trans 1 & -961.094260 & 0.00 \\
$N$-H trans 2 & -961.091614 & 1.66 \\
$N-\mathrm{H}$ cis 1 & -961.083843 & 6.54 \\
$N-\mathrm{H}$ cis 2 & -961.074860 & 12.17 \\
$N-\mathrm{Me}$ trans 1 & -1000.35997 & 2.91 \\
$N-\mathrm{Me}$ trans 2 & -1000.36460 & 0.00 \\
$N-\mathrm{Me}$ cis 1 & -1000.36260 & 1.25 \\
$N-\mathrm{Me}$ cis 2 & -1000.36356 & 0.65
\end{tabular}

[a] Refers to the cis and trans conformation around the amide $\mathrm{C}-\mathrm{N}$ bond.

conformation of the enamine has a big influence on the stereochemical outcome of the reaction and any change in the relative stability of the enamines would lead to a reducution in the selectivity observed.

A more detailed study of the conformation of the amide side was then undertaken, where the relative energies of cis versus trans amides were examined depending on whether the amide nitrogen atom was methylated or not. The results show (see details in Supporting Information) that for the $\mathrm{N}-\mathrm{H}$ cases there is a clear preference for the amide to assume the trans conformation (Table 3). However, when the corresponding $N$-Me derivatives were examined the energy differences between the cis and trans conformers were much less. As part of these calculations conformers formed by rotation around the $\mathrm{C}-\mathrm{C}$ bond between the pyrrolidine $\alpha$-carbon and amide carbonyl carbon were also examined, with the two lowest energy conformers being mentioned in each case (e.g., $N$-H trans 1 and $N$-H trans 2 in Table 3 ).

One further suggestion for an explanation of the reduction in stereoselctivity in going from the $N-\mathrm{H}$ amide side-chain to a $N$-Me side-chain was that there may be a $\mathrm{H}$-bonding interaction between the $N$-H and the nitro group of the trans- $\beta$-nitrostyrene. The relative energies of transition states derived from the reaction of the various enamines with trans- $\beta$-nitrostyrene were next investigated, with trajectories from above and beneath the enamine (both syn and anti) being examined, after a large number of individual calculations (see Supporting Information). The activation energy (15.43 $\mathrm{kcal} \mathrm{mol}^{-1}$ ) for the $\mathbf{S i}, \mathbf{S i}-\mathbf{1}$ trajectory (Figure 3) was $4.37 \mathrm{kcal} \mathrm{mol}^{-1}$ lower than the $\boldsymbol{R e}, \boldsymbol{R e}$ $\boldsymbol{I}$ trajectory $\left(19.80 \mathrm{kcal} \mathrm{mol}^{-1}\right)$. Furthermore, in all 
cases involving an $\mathrm{H}$-bond between the amide $\mathrm{N}-\mathrm{H}$ and the nitro group of the nitrostyrene, the energies of all such trajectories were much higher than the approach directed by the 4-hydroxy group, with the lowest activation energy found being $21.43 \mathrm{kcal} \mathrm{mol}^{-1}$. Similar activation energies were found when the amide side-chain was $N$-methylated $\left(21.45 \mathrm{kcal} \mathrm{mol}^{-1}\right)$. It seems that what is really important for this catalyst system is the structure of the amide sidechain and its effect on the relative stability of the $E$-enamines derived from each catalyst. A particular side-chain has an effect on the equilibria shown in the transition state model in Figure 3 (i.e. which trajectory predominates) which in turn governs the selectivity observed experimentally. We are currently undertaking further computational studies to examine differences in the relative energies between the transition states and activation energies that lead to the syn and anti products being formed in this catalytic system. The results of all these studies will be published in due course.

\section{Conclusions}

In conclusion we have prepared and studied a very wide range of 4-hydroxyprolinamides as catalysts for the asymmetric Michael addition reaction. It is apparent from these studies that the trans-4-hydroxy group is crucial for controlling the facial selectivity of the reactions. What is also apparent is that any compounds with a methyl group in the 2-position of the pyrrolidine ring show much reduced reactivity and stereocontrol as catalysts, and even the presence of the trans-4-hydroxy which directs the reaction electronically is unable to overcome the steric effect of the 2methyl group. The simplest trans-4-hydroxyprolinamides show the best reactivity with isolated yields of $98 \%$ being obtained using low catalyst loadings of only $5 \mathrm{~mol} \%$, while they also demonstrate complete stereocontrol. Within this subset of catalysts the results show that the exact structure of the prolinamide side-chain is critical to a successful outcome. Very small changes in the side-chain (e.g., $N$-H to $N$-Me or a phenyl to a naphthyl group) lead to large losses in the efficient control of the reaction. A large number of computational studies were undertaken to try to understand the stereochemical results. All the computational results show the importance of using the exact substrates used experimentally because very small changes in the structure of substrates can lead to profound differences in the stabilities of the enamines and transition states derived from them (see the Supporting Information). Attempts to use simplified structures in order to speed up the calculations could lead to spurious results not comparable with the actual experimental results found. It is clear that further studies are required, not just for these catalysts, but also for many other structural classes in order to improve the overall understanding of their structurereactivity relationships.

\section{Experimental Section}

\section{General Procedure for the Michael Addition Reaction of Aldehydes}

To a solution of the $\beta$-nitrostyrene $(1.00 \mathrm{mmol})$ in dry DCM $(1 \mathrm{~mL})$ was added the relevant catalyst $(0.05 \mathrm{mmol})$, followed by the aldehyde $(1.50 \mathrm{mmol})$. The reaction was stirred at ambient temperature for 2-3 days under nitrogen. It was then diluted with chloroform $(5 \mathrm{~mL})$ and treated with $1 \mathrm{~N}$ $\mathrm{HCl}(4 \mathrm{~mL})$ while stirring vigorously. The aqueous layer was extracted with chloroform and the combined organic layers were dried over $\mathrm{MgSO}_{4}$, and concentrated under vacuum. The crude product was purified by column chromatography using silica gel with 5\% ethyl acetate: petroleum ether.

For the synthesis and characterisation of all new compounds and products see the Supporting Information.

\section{X-Ray Data}

The data were collected at $150(2) \mathrm{K}$ on a Bruker Apex II CCD diffractometer. The structure was solved by direct methods ${ }^{[13]}$ and refined on $\mathrm{F}^{2}$ using all the reflections. ${ }^{[14]}$ All the non-hydrogen atoms were refined using anisotropic atomic displacement parameters and hydrogen atoms bonded to carbon and nitrogen were inserted at calculated positions using a riding model. The $\mathrm{H}$ atoms bonded to oxygen were located from difference maps and refined with thermal parameters riding on the carrier atoms.

Crystal data for $17 \mathbf{a} \cdot \mathrm{H}_{2} \mathrm{O}: \mathrm{C}_{19} \mathrm{H}_{30} \mathrm{~N}_{2} \mathrm{O}_{5} \cdot \mathrm{H}_{2} \mathrm{O}, M=366.445$ orthorhombic, $\quad a=8.9076(7), \quad b=9.4253(7), \quad c=$ 23.1459(18) $\AA, U=1943.3(3) \AA^{3}, T=150(2) \mathrm{K}$, space group $P 2_{1} 2_{1} 2_{1}, Z=4,19849$ reflections measured, 2759 independent reflections $\left(R_{\text {int }}=0.0291\right)$. The final $w \mathrm{R}(F 2)$ was 0.0819 (all data) and R1 was 0.0302 for $I>2 \mathrm{~s}(I)$. CCDC 807941 contains the supplementary crystallographic data for this paper. These data can be obtained free of charge from The Cambridge Crystallographic Data Centre via www.ccdc.cam.ac.uk/data_request/cif or on application to CCDC, 12 Union Road, Cambridge CB2 1EZ, UK (fax: +44-(0)1223-336033 or e-mail: deposit@ccdc.cam.ac.uk).

\section{Acknowledgements}

We are grateful to Strand I of the Irish Government's National Development Plan Technological Sector Research Programme and the ITT Dublin PhD Continuation Fund for funding for $J W$ and $L L$.

\section{References}

[1] a) T. Tokoroyama, Eur. J. Org. Chem. 2010, 2009-2016; b) D. Roca-Lopez, D. Sadaba, I. Delso, R. P. Herrera, T. Tejero, P. Merino, Tetrahedron: Asymmetry 2010, 21, 
2561-2601; c) S. B. Tsogoeva, Eur. J. Org. Chem. 2007 , 1701-1716; d) J. L. Vicario, D. Badía, L. Carillo, Synthesis 2007, 2065-2092; e) D. Almaşi, D. A. Alonso, C. Nájera, Tetrahedron: Asymmetry 2007, 18, 299-365.

[2] For a selection of recent reviews see refs. ${ }^{[1 \mathrm{~b}-\mathrm{e}]}$ and a) K. Jensen, G. Dickmeiss, H. Jiang, Ł. Albrecht, K. A. Jørgensen, Acc. Chem. Res. 2011, DOI:10.1021/ar200149w; b) Enantioselective Organocatalyzed Reactions I, (Ed.: R. Mahrwald), Springer, Berlin, Heidleberg, 2011; c) Enantioselective Organocatalyzed Reactions II, (Ed.: R. Mahrwald), Springer, Berlin, Heidelberg, 2011; d) Ł. Albrecht, H. Jiang, K. A. Jørgensen, Angew. Chem. 2011, 123, 8642-8660; Angew. Chem. Int. Ed. 2011, 50, 8492-8509; e) E. Marqués-López, R. P. Herrera, Curr. Org. Chem. 2011, 15, 2311-2327; f) P.H-Y. Cheong, C. Legault, J. Um, N. Çelebi-Ölçüm, K. Houk, Chem. Rev. 2011, 111, 5042-5137; g) M. Nielsen, D. Worgull, T. Zweifel, B. Gschwend, S. Bertelsen, K. A. Jørgensen, Chem. Commun. 2011, 47, 632-649; h) J. L. Vicario, D. Badia, L. Carillo, E. Reyes, Organocatalytic Enantioselective Conjugate Addition Reactions, RSC Publishing, Cambridge, 2010; i) G. Valero, X. Companyó, N. Bravo, A-N. R. Alba, A. Moyano, R. Rios, Synlett 2010, 1883 1908; j) L-W. Xu, L. Li, Z-H. Shi, Adv. Synth. Catal. 2010, 352, 243-279; k) A. Lattanzi, Chem. Commun. 2009, 1452-1463; 1) A. Dondoni, A. Massi, Angew. Chem. 2008, 120, 4716-4739; Angew. Chem. Int. Ed. 2008, 47, 4638-4660; m) P. Melchiore, M. Marigo, A Carlone, G. Bartoli, Angew. Chem. 2008, 120, 6232 6265; Angew. Chem. Int. Ed. 2008, 47, 6138-6171; n) H. Kotsuki, H. Ikishima, A. Okuyama, Heterocycles 2008, 75, 757-797; o) D. Longbottom, V. Franckevičius, S. Kumarn, A. Oelke, V. Wascholowski, S. Ley, Aldrichimica Acta 2008, 41, 3-11; p) S. Sulzer-Mossé, A. Alexakis, Chem. Commun. 2007, 3123-3135; q) S. Mukherjee, J. W. Yang, S. Hoffman, B. List, Chem. Rev. 2007, 107, 5471-5569; r) M. Gaunt, C. Johansson, A. McNally, N. Vo, Drug Discovery Today 2007, 12, 8-27; s) H. Pellissier, Tetrahedron 2007, 63, 9267-9331; t) Enantioselective Organocatalysis: Reactions and Experimental Procedures, (Ed.: P. Dalko), Wiley-VCH, Weinheim, 2007; u) S. Mossé, O. Andrey, A. Alexakis, Chimia 2006, 60, 216-219; v) Asymmetric Organocatalysis: From Biomimetic Concepts to Applications in Asymmetric Synthesis, (Eds.: A. Berkessel, H. Gröger), Wiley-VCH, Weinheim, 2005; w) A. Cobb, D. Shaw, D. Longbottom, J. Gold, S. Ley, Org. Biomol. Chem. 2005, 3, 84-96; x) W. Notz, F. Tanaka, C. Barbas III, Acc. Chem. Res. 2004, 37, 580-591, and references cited therein.

[3] Source: Web Of Science. ISI Thomson Reuters, 2011.

[4] S. Zhu, S. Yu, D. Ma, Angew. Chem. 2008, 120, 555558; Angew. Chem. Int. Ed. 2008, 47, 545-548.
[5] M. Lombardo, M. Chiarucci, A. Quintavalla, C. Trombini, Adv. Synth. Catal. 2009, 351, 2801-2806.

[6] Z. Zheng, B. L. Perkins, B. Ni, J. Am. Chem. Soc. 2010, 132, 50-51;

[7] a) M. Wiesner, G. Upert, G. Angelici, H. Wennemers, J. Am. Chem. Soc. 2010, 132, 6-7; b) M. Wiesner, J. Revell, S. Tonazzi, H. Wennemers, J. Am. Chem. Soc. 2008, 130, 5610-5611; c) M. Wiesner, J. Revell, H. Wennemers, Angew. Chem. 2008, 120, 1897-1900; Angew. Chem. Int. Ed. 2008, 47, 1871-1874, and references cited therein.

[8] Ref. ${ }^{[2]}$ and K. Patora-Komisarska, M. Benohoud, H. Ishikawa, D. Seebach, Y. Hayashi, Helv. Chim. Acta 2011, 94, 719-745.

[9] F. Kelleher, S. Kelly, J. Watts, V. McKee, Tetrahedron 2010, 66, 3525-3536.

[10] C. Palomo, S. Vera, A. Mielgo, E. Gómez-Bengoa, Angew. Chem. 2006, 118, 6130-6133; Angew. Chem. Int. Ed. 2006, 45, 5984-5987, and references cited therein.

[11] Y. Okuyama, H. Nakano, Y. Watanabe, M. Makabe, M. Takeshita, K. Uwai, C. Kabuto, E. Kwon, Tetrahedron Lett. 2009, 50, 193-197.

[12] a) J. Peng, D. L. Clive, Org. Lett. 2007, 9, 2939-2941; b) T. Sato, S. Kawasaki, N. Oda, S. Yagi, S. El Bialy, J. Uenishi, M. Yamauchi, M. Ikeda, J. Chem. Soc. Perkin Trans. 1 2001, 2623-2631.

[13] M. J. Frisch, G. W. Trucks, H. B. Schlegel, G. E. Scuseria, M. A. Robb, J. R. Cheeseman, J. A. Montgomery Jr, T. Vreven, K. N. Kudin, J. C. Burant, J. M. Millam, S. S. Iyengar, J. Tomasi, V. Barone, B. Mennucci, M. Cassi, G. Scalmani, N. Rega, G. A. Petersson, H. Nakatsuji, M. Hada, M. Ehara, K. Toyota, R. Fukuda, J. Hasegawa, M. Ishida, T. Nakajima, Y. Honda, O. Kitao, H. Nakai, M. Klene, X. Li, J. E. Knox, H. P. Hratchian, J. B. Cross, C. Adamo, J. Jaramillo, R. Gomperts, R. E. Stratmann, O. Yazyev, A. J. Austin, R. Cammi, C. Pomelli, J. W. Ochterski, P. Y. Ayala, K. Morokuma, G. A. Voth, P. Salvador, J. J. Dannenberg, V. G. Zakrzewski, S. Dapprich, A. D. Daniels, M. C. Strain, O. Farkas, D. K. Malick, A. D. Rabuck, K. Raghavachari, J. B. Foresman, J. V. Ortiz, Q. Cul, A. G. Baboul, S. Clifford, J. Cioslowski, B. B. Stefanov, G. Lin, A. Liashenko, P. Piskorz, L. Komaromi, R. L. Martin, D. J. Fox, T. Keith, M. A. Al-Laham, C. Y. Peng, A. Nanayakkara, M. Challacombe, P. M. W. Gill, B. Johnson, W. Chen, M. W. Wong, C. Gonzalez, J. A. Pople, Gaussian 03, Gaussian, Inc., Wallingford, CT, 2004.

[14] M. Burla, R. Caliandro, M. Camalli, B. Carrozzini, G. Cascarano, L. Caro, C. Giacovazzo, G. Polidori, R. Spagna, ( SIR-2004), J. Appl. Cryst. 2005, 38, 381.

[15] G. M. Sheldrick, Acta Crystallogr. Sect. A 2008,64, 112122. 
Structure-Reactivity Studies of Simple 4-

Hydroxyprolinamide Organocatalysts in the Asymmetric Michael Addition Reaction of Aldehydes to Nitroolefins

Adv. Synth. Catal. 2012, 354, 1 -9

John Watts, Lien Luu, Vickie McKee, Ed Carey,

Fintan Kelleher*
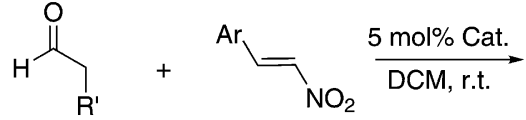

1.5 equiv.

$$
\mathrm{HO}
$$

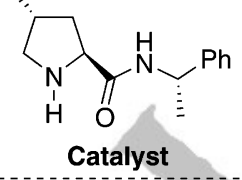

$\left.\right|_{\mathrm{R}^{\prime}} ^{\mathrm{Ph}} \mathrm{NO}_{2}$

$98 \%$ yield

99:1 syn/anti

up to $98 \%$ ee (syn) 